\title{
Batch Adsorption of Maxilon Red GRL from Aqueous Solution by Natural Sugarcane Stalks Powder
}

\author{
Gamal Owes El-Sayed, Talaat Younis Mohammed, and Ashraf Abd-Allah Salama \\ Chemistry Department, Faculty of Science, Benha University, Benha 13511, Egypt \\ Correspondence should be addressed to Gamal Owes El-Sayed; gamaloelsayed@yahoo.com
}

Received 23 May 2013; Accepted 1 July 2013

Academic Editors: F. Long, A. Waseem, and C. Waterlot

Copyright ( 2013 Gamal Owes El-Sayed et al. This is an open access article distributed under the Creative Commons Attribution License, which permits unrestricted use, distribution, and reproduction in any medium, provided the original work is properly cited.

Sugarcane stalks powder was tested for its efficiency of removing a textile dye Maxilon Red GRL from aqueous solution. Different parameters affecting dye removal efficiency were studied. These parameters include contact time, initial dye concentration, adsorbent dose, ionic strength, $\mathrm{pH}$, and temperature. Langmuir and Freundlich isotherm models were applied to the equilibrium data. The data fitted well with the Langmuir isotherm $\left(R^{2}>0.99\right)$. The maximum monolayer adsorption capacity $\left(Q_{0}\right)$ was found to be $20.96 \mathrm{mg} / \mathrm{g}$ at an initial $\mathrm{pH}$ of 7.2. The temperature variation study showed that dye adsorption is exothermic and spontaneous with increased randomness at the solid solution interface. The results indicated that sugarcane stalks could be an alternative for more costly adsorbents used for dye removal. The kinetic of the adsorption process followed the pseudo second-order kinetics model.

\section{Introduction}

The textile industry is among important sources of contamination responsible for the continuous pollution of the environment. Production of textiles and volume of wastewater containing processed textile dyes steadily increase [1]. Large amounts of the dyestuff are lost directly into wastewater and consequently have a detrimental effect on flora and fauna [2]. There are more than 100,000 dyes available commercially; most of which are difficult to decolorize due to their complex structure and synthetic origin as they are designed to resist fading upon exposure to different factors as light, water, and oxidizing agents and as such are very stable and difficult to degrade $[3,4]$. The polluting effects of dyes against aquatic environment can also be the result of toxic effects due to their long time presence in environment (i.e., half-life time of several years), accumulation in sediments but especially in fishes or other aquatic life forms, and decomposition of pollutants in carcinogenic or mutagenic compounds but also low aerobic biodegradability [5-7].

Various techniques have been employed for the removal of dyes from wastewaters including, physical, physicochemical, and chemical processes [8-12]. All these methods have different color removal capabilities, costs, and operating rates. One of the most effective and proven treatments with potential application in textile wastewater treatment is adsorption. This process has been found to be superior compared to other techniques for wastewater treatment in terms of its capability for efficiently adsorbing a broad range of adsorbates and its simplicity $[13,14]$. Adsorption process consists in the transfer of soluble organic dyes (solutes) from wastewater to the surface of solid, highly porous, particles (the adsorbent). The adsorbent has a finite capacity for each compound to be removed, and when is "spent" must be replaced by fresh material (it must be either regenerated or incinerated). The most important factors influencing dye adsorption efficiency are: dye/adsorbent interaction, adsorbent surface area, particle size, temperature, $\mathrm{pH}$, and contact time [15-17]. The most used adsorbent is activated carbon beside some other commercial inorganic adsorbents as bentonite, perlite, bauxite, and clays [18-21]. Some low cost adsorbents of agricultural wastes as peat, rice husk, neem leaf powder, tree barks, bagasse pith, wood chips, ground nut shell powder, rice hulls, wood sawdust, and grounded sunflower seed shells are also used for the removal of dyes from textile effluents [22-24]. The use of vegetarian natural materials is 
advantageous mainly due to their widespread availability and cheapness. Sometimes the regeneration is not necessary, and the "spent" material is conventionally burnt although there is potential for solid state fermentation (SSF) for protein enrichment.

In the present study, sugarcane stalks powder was used as a new low-cost adsorbent for the removal of a textile dye Maxilon Red GRL from aqueous solutions. Few studies were conducted for the removal of Maxilon Red GRL dye by adsorption onto mineral adsorbents as bentonite [25], kaolinite [26], and silica [27]. No study has been reported for the adsorption of the dye on agricultural wastes. The effect of different parameters such as $\mathrm{pH}$, temperature, contact time, initial adsorbent dose, and initial dye concentration were investigated. Finally, the isotherm and thermodynamic parameters for the adsorption of Maxilon Red GRL dye onto sugarcane stalks powder were evaluated.

\section{Experimental}

2.1. Materials. All chemicals used were of analytical grade and were used without further purifications. The dye was obtained from commercial market. Stock solution of Maxilon Red GRL dye contains $200 \mathrm{mg}$ dye/L and was prepared by dissolving the dye in double distilled water. The working solutions were obtained by diluting the stock solution with twice distilled water. The chemical structure of Maxilon Red GRL dye is 1,2-dimethyl-3-((4-(methyl(phenylmethyl) amino)phenyl)azo)-1,2,4-tetrazolium bromide (Figure 1).

2.2. Preparation of Sugarcane Stalks. Sugarcane stalks residues were collected from the cultivated area around Benha city and then washed several times with distilled water to remove dust. The samples were sun dried for $48 \mathrm{hrs}$ and dried again in a drying oven overnight at $80^{\circ} \mathrm{C}$. The dried stalks samples were ground sieved through a $1 \mathrm{~mm}$ sieve and kept dry in a closed container till use.

2.3. Determination of $p H$ of Point of Zero Charge $\left(p H_{p z c}\right)$ of the Adsorbent. In order to determine the $\mathrm{pH}$ of point of zero charge, $0.15 \mathrm{~g}$ of sugarcane stalks was taken to different $100 \mathrm{~mL}$ conical flasks containing $50 \mathrm{~mL}$ of $0.01 \mathrm{M} \mathrm{NaCl}$; the $\mathrm{pH}$ of which was adjusted from 2 to 10 by addition of $0.01 \mathrm{M}$ $\mathrm{HCl}$ or $\mathrm{NaOH}$ for each flask. The conical flasks were sealed and placed in a shaker for 24 hours. The content of the flasks was filtered, and $\mathrm{pH}$ was then measured by $\mathrm{pH}$ meter.

2.4. Batch Adsorption Studies. Batch adsorption experiments were carried out at room temperature $\left(25^{\circ} \mathrm{C} \pm 1\right)$. Exactly $25 \mathrm{~mL}$ of dye solution of known initial concentration $(50 \mathrm{mg} / \mathrm{L})$ was stirred at a constant stirring rate $(400 \mathrm{rpm})$ with a required dose of adsorbents (0.05-0.2 g) for a specific period of contact time (15-120 min) using a magnetic stirrer, after noting down the initial $\mathrm{pH}$ of the solution to the optimum $\mathrm{pH}$. The $\mathrm{pH}$ of the solutions was adjusted to the required value by adding either $1 \mathrm{M} \mathrm{HCl}$ or $1 \mathrm{M} \mathrm{NaOH}$ solution. After equilibrium, the final concentration $\left(C_{e}\right)$ was measured using absorbance values with a JascoV-530

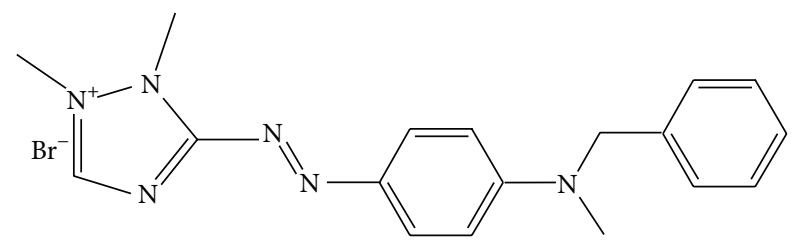

Figure 1: Chemical structure of Maxilon Red GRL dye.

(UV-Vis) spectrophotometer (Japan) and compared with the absorbance value of the initial solutions $\left(C_{0}\right)$. The absorbance was measured at $530 \mathrm{~nm}$. Experiments were carried out in duplicate, and mean values are presented. The percentage removal of dye was calculated using the following equation:

$$
\% \text { Dye Removal }=\frac{C_{0}-C_{e}}{C_{0}},
$$

where $C_{0}$ and $C_{e}$ are the initial and final (equilibrium) concentrations of dye $(\mathrm{mg} / \mathrm{L})$, respectively. Blanks containing second distilled water were used for each series of experiments as controls. The amount of dye adsorption per unit mass of sugarcane stalks powder at equilibrium $q_{e}(\mathrm{mg} / \mathrm{g})$ was calculated by the following equation:

$$
q_{e}=\frac{\left(C_{0}-C_{e}\right) V}{W},
$$

where $V$ is the volume of the dye solution $(\mathrm{mL})$ and $W$ is the weight of adsorbent (g) added to volume $V$.

\section{Results and Discussion}

3.1. Point of Zero Charge $\left(\mathrm{pH}_{p z c}\right)$ of the Adsorbent. $\mathrm{pH}_{\mathrm{pzc}}$ of an adsorbent is important because it indicates the net surface charge of the adsorbent in solution. The $\mathrm{pH}_{\mathrm{pzc}}$ is the point where the curve of $\mathrm{pH}_{\text {final }}$ versus $\mathrm{pH}_{\text {initial }}$ intersects the line $\mathrm{pH}_{\text {initial }}=\mathrm{pH}_{\text {final }}$ (Figure 2). The point of zero charge of sugarcane stalks was determined as 4.8 .

3.2. Effect of Contact Time and Initial Dye Concentration. The effect of contact time on the percentage color removal of the dye was investigated at different initial dye concentrations 25 , 50,75 , and $100 \mathrm{mg} / \mathrm{L}$ as shown in Figure 3. The percentage removal of dye by sugarcane stalks powder was rapid in the beginning due to larger surface area available of adsorbent, but it gradually decreased with time until it reached equilibrium. The plot reveals maximum percent removal of the dye after about $60 \mathrm{~min}$ of continuous stirring. From Figure 3, it is clear that the removal of dye was dependent on the concentration of the dye, and the process was faster at higher concentrations. While the percent of color removal decreases with increasing initial dye concentration $\left(C_{0}\right)$ from $91.0 \%$ at $25 \mathrm{mg} / \mathrm{L}$ to $26.4 \%$ at $100 \mathrm{mg} / \mathrm{L}$, the adsorption capacity $\left(q_{e}\right)$ increased from $11.37 \mathrm{mg} / \mathrm{g}$ to $13.20 \mathrm{mg} / \mathrm{g}$, respectively. The shapes of the curves are similar and approximately independent on the initial dye concentration which indicates a monolayer formation of the dye on the external surface [28]. A similar trend was reported for the adsorption of dyes onto different biosorbents [29-32]. 


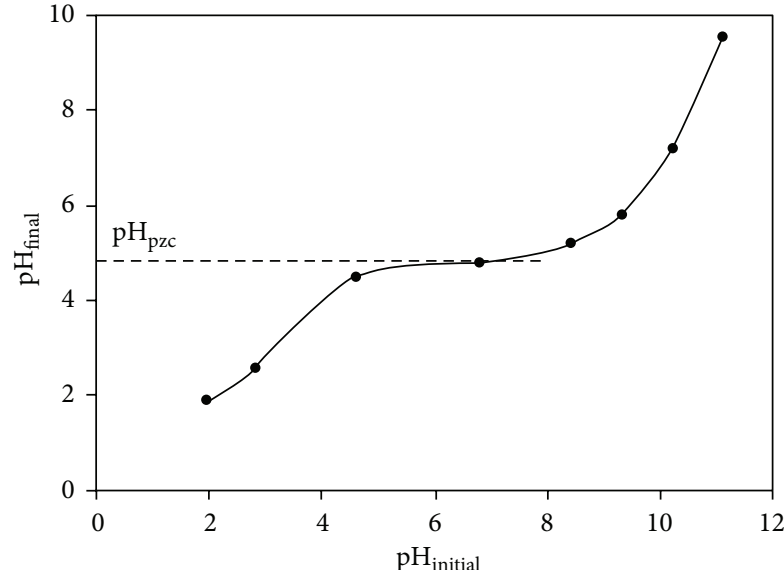

FIGURE 2: Determination of point of zero charge of sugarcane stalks powder.

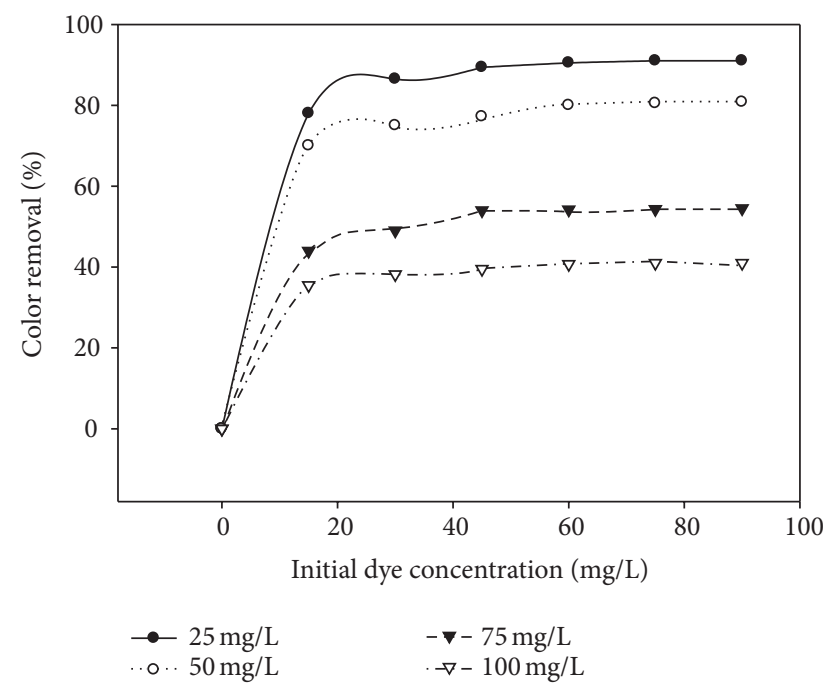

FIgURE 3: Relation between contact time and dye color removal at different Maxilon Red GRL concentrations.

3.3. Effect of $p H$. The initial $\mathrm{pH}$ of the adsorbate solution plays an important role in the adsorption capacity. The effect of initial $\mathrm{pH}$ of dye solution on the percentage removal of dye was studied by varying the initial $\mathrm{pH}$ (1.9-10.8) under constant process parameters. The results are shown in Figure 4. The dye adsorbed by sugarcane stalks was lower at lower $\mathrm{pH}$, and its maximum values attained at $\mathrm{pH}$ values higher than 4.5 , so the optimum $\mathrm{pH}$ was attained at slightly acidic or neutral solutions. Maximum removal of the dye (about $84.2 \%$ ) was achieved at $\mathrm{pH} 4.8$. As the $\mathrm{pH}$ was decreased from 4.8 to 1.9 , the removal percent decreased to $7.6 \%$. This behavior is expected and can be explained by considering the $\mathrm{pH}_{\mathrm{zpc}}$ of the adsorbent as well as molecular nature of Maxilon Red GRL (as a cationic molecule). The $\mathrm{pH}_{\mathrm{zpc}}$ of the adsorbent is 4.8 , meaning that the adsorbent's surface is positively charged at solution pHs below 4.8. This causes competition between protons and dye cations for adsorption locations [33]. Above the value of $\mathrm{pH}_{\mathrm{pzc}}$, a negative charge is present on the surface

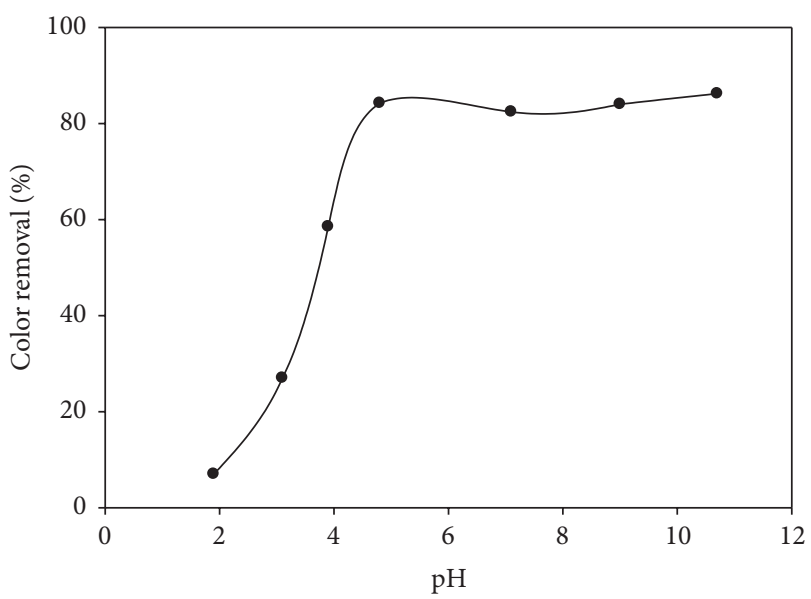

FIGURE 4: Effect of solution $\mathrm{pH}$ on the dye color removal on sugarcane stalks powder.

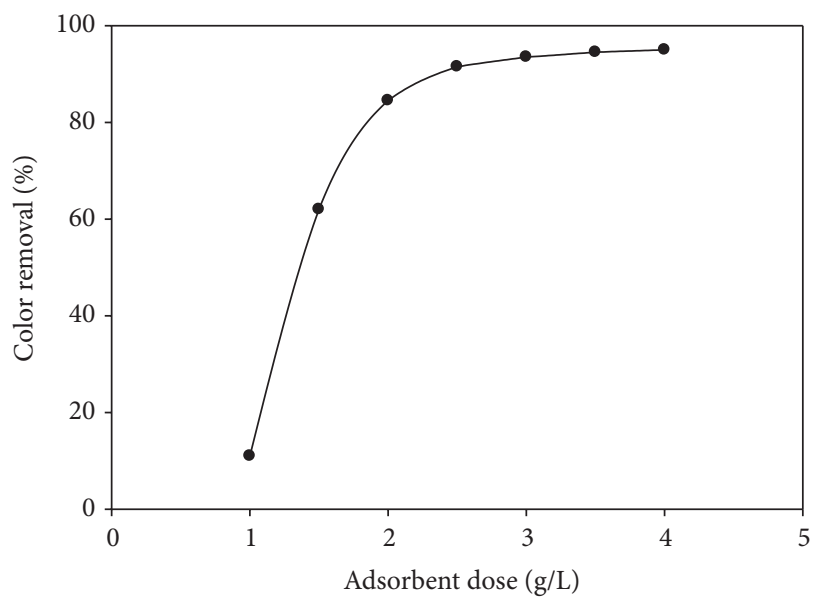

FIGURE 5: Effect of adsorbing dose of sugarcane stalks powder on the color removal of Maxilon Red GRL.

of sugarcane stalks causing better dye cations adsorption through the electrostatic attraction.

3.4. Effect of Adsorbent Dose. The influence of adsorbent dose on dye removal by sugarcane stalks powder was performed in a range of $0.5-2 \mathrm{~g} / \mathrm{L}$ under the conditions specified in Figure 5. The percentage of the dye removal after equilibrium time increased from $11.25 \%$ to $95.10 \%$ as the adsorbent dose was increased from 1.0 to $4.0 \mathrm{~g} / \mathrm{L}$. The increased removal at high dosages is expected because of the increased adsorbent surface area and availability of more adsorption sites [34].

3.5. Effect of Ionic Strength. Generally, various salts and metal ions exist in dye containing wastewater. These salts lead to high ionic strength, which may affect the dye adsorption onto various adsorbents. Figure 6 shows the effect of ionic strength on Maxilon Red GRL uptake from aqueous solution by sugarcane stalks. It was observed that the presence of $\mathrm{NaCl}$ decreased the amount of dye adsorbed on sugarcane stalks at equilibrium $\left(q_{e}\right)$. Because the adsorption of basic dyes is likely 


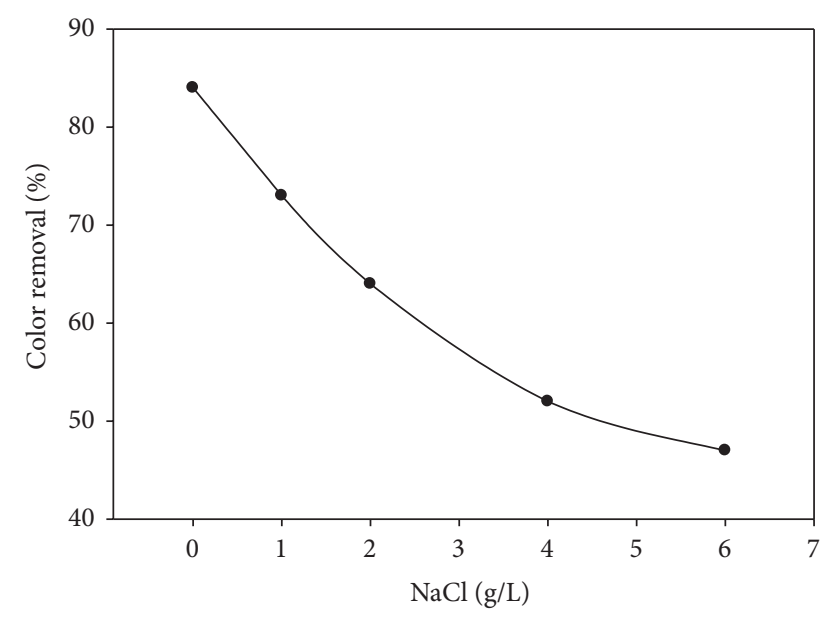

FIgURE 6: Effect of salinity on Maxilon Red GRL removal onto sugarcane stalks powder.

to be dominated by ion-exchange processes [35], the results may be explained in terms of the competition between dye and the cations in the added salt for the binding sites in the adsorbent. This increase is expected and previously reported [36].

3.6. Adsorption Isotherms. The adsorption data were analyzed using adsorption isotherm models, Langmuir and Freundlich. The Langmuir model is based on the assumption that maximum adsorption corresponds to a saturated monolayer of solute molecules on the adsorbent surface. The expression of the Langmuir model is given by the following equation [37]:

$$
q_{e}=\frac{Q_{0} b C_{e}}{1+b C_{e}},
$$

where $q_{e}(\mathrm{mg} / \mathrm{g})$ and $C_{e}(\mathrm{mg} / \mathrm{L})$ are the amounts of adsorbed dye per unit mass of sorbent and dye concentration in solution at equilibrium, respectively. $Q_{0}$ is the maximum amount of the adsorbed dye per unit mass of sorbent to form a complete monolayer on the surface bound at high $C_{e}$ $(\mathrm{mg} / \mathrm{g})$, and $b(\mathrm{~L} / \mathrm{mg})$ is a constant related to the affinity of the binding sites on the adsorbent surface. The linear form of the Langmuir equation is written as follows:

$$
\frac{C_{e}}{q_{e}}=\frac{1}{b Q_{0}}+\frac{C_{e}}{Q_{0}} .
$$

A plot of $\left(C_{e} / q_{e}\right)$ versus $C_{e}$ should be a straight line with a slope of $1 / Q_{0}$ and intercept $1 / Q_{0} b$. The essential characteristics of the Langmuir isotherm can be expressed in terms of a dimensionless constant separation factor $R_{L}$ that is given by the following equation [38]:

$$
R_{L}=\frac{1}{1+b C_{e}},
$$

where $C_{0}$ represents the initial concentration $(\mathrm{mg} / \mathrm{L})$ and $b$ the Langmuir constant related to adsorption energy $(\mathrm{L} / \mathrm{mg})$.

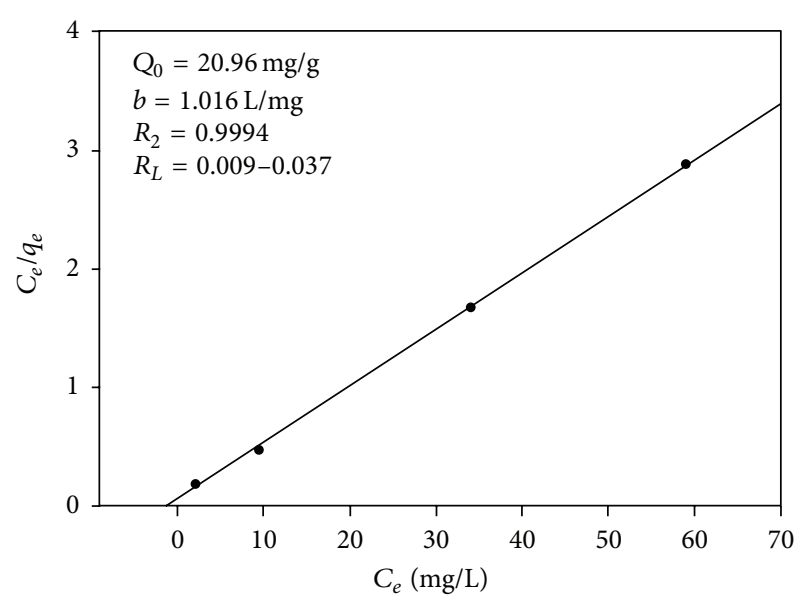

FIGURE 7: Langmuir isotherm for Maxilon Red GRL dye adsorption onto sugarcane stalks powder.

$R_{L}$ value implies the shape of the isotherms to be either unfavorable $\left(R_{L}\right)$, linear $\left(R_{L}=1\right)$, favorable $\left(0<R_{L}<\right.$ $1)$, or irreversible $\left(R_{L}=0\right)$. As can be seen in Figure 7, for the sorption system, $R_{L}$ values at different temperatures are between 0 and 1 , showing favorable adsorption $\left(C_{0}=\right.$ $50 \mathrm{mg} / \mathrm{L}$ ). All $R_{L}$ values at different temperatures and concentrations were between 0 and 1 . The Freundlich model assumes heterogeneous adsorption due to the diversity of active sites on the surface. The Freundlich equation is expressed as [39]

$$
q_{e}=K_{F} C_{e}^{1 / n},
$$

where $K_{F}(\mathrm{mg} / \mathrm{g})$ is an indicator of the biosorption capacity and $1 / n(\mathrm{~L} / \mathrm{mg})$ is the biosorption intensity. A value for $1 / n$ below one indicates a normal Freundlich isotherm while $1 / n$ above one is an indicative of cooperative adsorption. Equation (6) can be written in the logarithmic form as

$$
\log q_{e}=\log K_{F}+\frac{1}{n} \log C_{e} .
$$

A plot of $\log q_{e}$ versus $\log C_{e}$ is shown in Figure 8, where the values of $K_{F}$ and $1 / n$ are determined from the intercept and slope of the linear regressions. As seen, a very high regression correlation coefficient was shown by the Langmuir model $\left(R^{2}=0.9994\right)$. This indicates that the Langmuir model was very suitable for describing the sorption of Maxilon Red GRL dye on sugarcane stalks powder compared to Freundlich model $\left(R^{2}=0.7649\right)$.

The maximum capacity $Q_{0}$ determined from the Langmuir isotherm defines the total capacity of the sugarcane stalks for the dye as $20.96 \mathrm{mg} / \mathrm{g}$ sorbent. The fact that the Langmuir isotherm fits the experimental data compared to Freundlich isotherm may be due to the homogeneous distribution of active sites on the surface of sorbent.

3.7. Effect of Temperature and Thermodynamic Parameters. Adsorption experiments were carried out for $25 \mathrm{~mL}$ dye solution containing $50 \mathrm{mg} / \mathrm{L}$ at three different temperatures $\left(21,32\right.$, and $\left.45^{\circ} \mathrm{C}\right)$ using $0.05 \mathrm{~g}$ of adsorbent in order to follow 


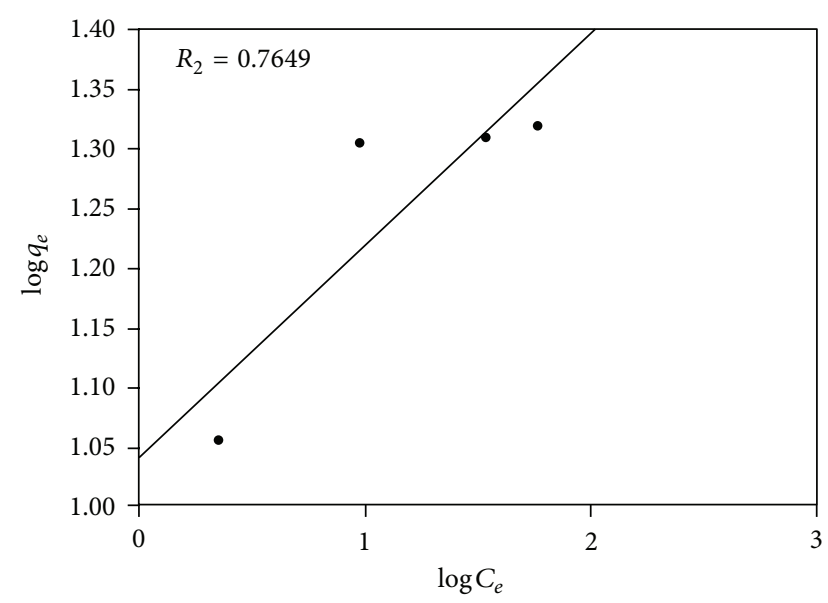

FIGURE 8: Freundlich isotherm for Maxilon Red GRL dye adsorption onto sugarcane powder.

the effect of temperature on the adsorption capacity. It was observed that with an increase in temperature, adsorption capacity decreased. In order to explain and confirm the mechanism of Maxilon Red GRL adsorption onto sugarcane stalks, the thermodynamic parameters including Gibbs free energy change $\left(\Delta G^{\circ}\right)$, enthalpy change $\left(\Delta H^{\circ}\right)$, and entropy change $\left(\Delta S^{\circ}\right)$ were calculated from the following equations [40]:

$$
\begin{gathered}
K_{s}=\frac{C_{\text {solid }}}{C_{\text {liquid }}}, \\
\Delta G^{\circ}=-R T \ln K_{s}, \\
\ln K_{s}=\frac{\Delta S^{\circ}}{R}-\frac{\Delta H^{\circ}}{R T},
\end{gathered}
$$

where $K_{s}$ is the equilibrium constant, $C_{\text {solid }}$ is the solid phase concentration at equilibrium $(\mathrm{mg} / \mathrm{L}), C_{\text {liquid }}$ is the liquid phase concentration at equilibrium $(\mathrm{mg} / \mathrm{L}), T$ is the temperature in Kelvin, and $R$ is the gas constant $(8.314 \mathrm{~J} / \mathrm{mol}$ K).

By plotting a graph of $\ln K_{s}$ versus $1 / T$ (Figure 9), the values of $\Delta H^{\circ}$ and $\Delta S^{\circ}$ can be estimated from the slopes and intercepts, respectively (Table 1). The linear correlation coefficient value $\left(R^{2}=0.9979\right)$ indicates good linearity. The negative value of $\Delta H^{\circ}$ indicates that the sorption reaction is exothermic [41]. The positive value of $\Delta S^{\circ}$ shows the increasing randomness at the solid/liquid interface during the sorption of Maxilon Red on sugarcane stalks.

The negative values of $\Delta G^{\circ}$ (Table 1) indicate the feasibility of the process and the spontaneous nature of adsorption at studied temperatures. It has been resported that $\Delta G^{\circ}$ values up to $-20 \mathrm{~kJ} / \mathrm{mol}$ are consistent with electrostatic interaction between sorption sites and the metal ion (physical adsorption), while $\Delta G^{\circ}$ values more negative than $-40 \mathrm{~kJ} / \mathrm{mol}$ involve charge sharing or transfer from the adsorbent surface to the adsorbate to form a coordinate bond (chemical adsorption) [42]. The $\Delta G^{\circ}$ values obtained in this study are

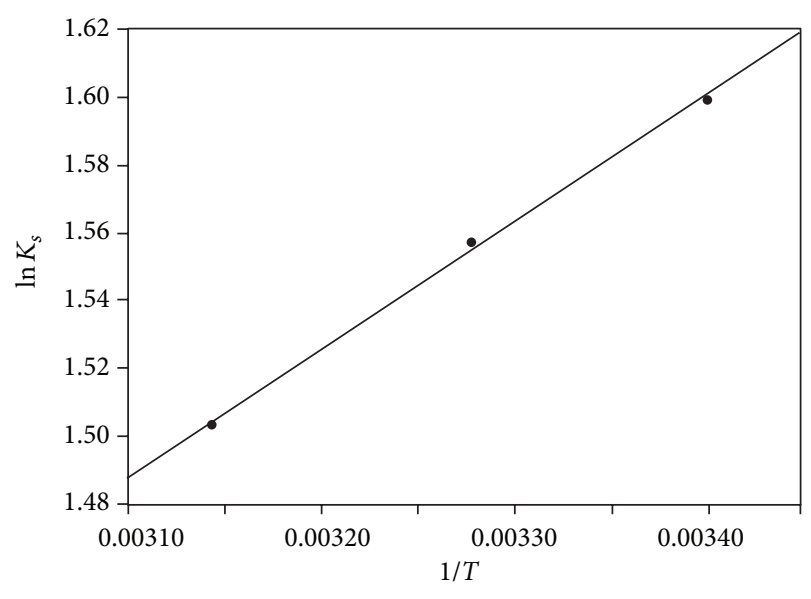

FIGURE 9: Plot of $\ln K_{s}$ versus $1 / T$ for adsorption of Maxilon Red GRL on sugarcane stalks powder.

TABLE 1: Thermodynamic parameters for the adsorption of Maxilon Red GRL on sugarcane stalks powder.

\begin{tabular}{lcccc}
\hline \multirow{2}{*}{$\Delta H^{\circ}(\mathrm{kJ} / \mathrm{mol})$} & \multirow{2}{*}{$\Delta S^{\circ}(\mathrm{kJ} / \mathrm{mol} \mathrm{K})$} & \multicolumn{3}{c}{$\Delta G^{\circ}(\mathrm{kJ} / \mathrm{mol})$} \\
& & $294 \mathrm{~K}$ & $305 \mathrm{~K}$ & $318 \mathrm{~K}$ \\
\hline-3.122 & 2.692 & -3.908 & -3.948 & -3.973 \\
\hline
\end{tabular}

$<-10 \mathrm{~kJ} / \mathrm{mol}$, which indicate that physical adsorption was the predominant mechanism in the sorption process [43].

3.8. Kinetics of Adsorption. Many kinetic models have been proposed to elucidate the mechanism of solute adsorption. These models are useful for the design and optimization of effluent treatment process. In order to investigate the mechanism of Maxilon Red GRL dye adsorption by sugarcane stalks, two kinetic models were considered.

3.8.1. Pseudo First-Order Kinetic Model. The integrated linear form of pseudo first-order kinetic model proposed by Lagergren [44] is

$$
\ln \left(q_{e}-q_{t}\right)=\ln q_{e}-k_{1} t
$$

where $q_{e}$ is the amount of dye adsorbed at equilibrium $(\mathrm{mg} / \mathrm{g}), q_{t}$ is the amount of dye adsorbed at time $t(\mathrm{mg} / \mathrm{g})$, $k_{1}$ is the first order rate constant $\left(\mathrm{min}^{-1}\right)$ and $t$ is the time (min). Hence, a linear trace is expected between the two parameters $\log \left(q_{e}-q_{t}\right)$ and $t$ (Figure 10), provided the adsorption follows first order kinetics. The values of $k_{1}$ and $q_{e}$ can be determined from the slope and intercept. The pseudo first order rate constant ranged between $5.47 \times 10^{-2} \mathrm{~min}^{-1}$ to $7.92 \times 10^{-2} \mathrm{~min}^{-1}$. The low $R^{2}$ values (Table 2 ) suggest that the adsorption data fitted poor to pseudo first-order kinetics. Hence, the adsorption of Maxilon Red GRL onto sugarcane stalks may not follow the pseudo first order rate expression.

3.8.2. Pseudo Second-Order Kinetic Model. The adsorption may also be described by a pseudo second-order kinetic 
TABLE 2: Comparison of the first-order and second-order adsorption rate constants and calculated and experimental $q_{e}$ values for different initial Maxilon Red GRL concentrations on sugarcane stalks powder.

\begin{tabular}{lccccc}
\hline \multirow{2}{*}{$C_{0}(\mathrm{mg} / \mathrm{L})$} & \multicolumn{3}{c}{ Pseudo first-order kinetics } & \multicolumn{3}{c}{ Pseudo second-order kinetics } \\
& $q_{e, \text { cal }}(\mathrm{mg} / \mathrm{g})$ & $k_{1}\left(\mathrm{~min}^{-1}\right)$ & $R^{2}$ & $q_{e, \text { cal }}(\mathrm{mg} / \mathrm{g})$ & $k_{2}(\mathrm{~g} / \mathrm{mg} \mathrm{min})$ \\
\hline 25 & 8.91 & $7.24 \times 10^{-2}$ & 0.9544 & 23.92 & $1.27 \times 10^{-2}$ \\
50 & 14.55 & $5.47 \times 10^{-2}$ & 0.9104 & 42.01 & 0.9999 \\
75 & 30.72 & $7.92 \times 10^{-2}$ & 0.9708 & 44.64 & $0.72 \times 10^{-2}$ \\
100 & 17.30 & $6.27 \times 10^{-2}$ & 0.9389 & 34.48 & $0.40 \times 10^{-2}$ \\
\end{tabular}

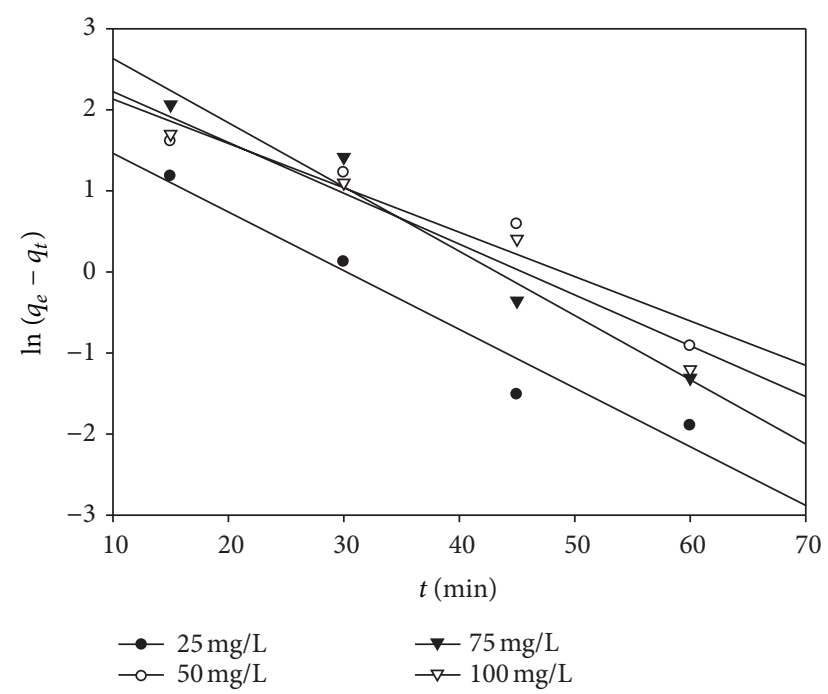

FIGURE 10: The pseudo first-order kinetics for the adsorption of Maxilon Red GRL on sugarcane stalks powder.

model [45]. The linearized form of the pseudo second-order model is

$$
\frac{t}{q_{t}}=\frac{1}{k_{2} q_{e}^{2}}+\frac{1}{q_{e}} t,
$$

where $k_{2}$ is the second order rate constant ( $\mathrm{g} / \mathrm{mg}$ min). A plot of $t / q_{t}$ and $t$ should be linear if the adsorption follows second order. $q_{e}$ and $k_{2}$ can be calculated from the slope and intercept of the plot (Figure 11). The correlation coefficients $\left(R^{2}\right)$ for the second-order kinetic model are between 0.9717 and 0.9999 (Table 2); therefore, the adsorption system is not a first-order reaction but fits the pseudo second-order kinetic model. The decrease of $R^{2}$ by increasing dye concentration indicates a possible change in the kinetic mechanism of adsorption with increasing concentration [46].

\section{Conclusion}

The results of different experiments showed that natural sugarcane stalks powder has an ability to adsorb Maxilon Red GRL dye from aqueous solution. The sorption process was found to be $\mathrm{pH}$ dependent, and the adsorption process has nearly reached equilibrium in $60 \mathrm{~min}$. The experimental data are fitted well to Langmuir isotherm model, and the maximum adsorptive quantity of Maxilon Red GRL was

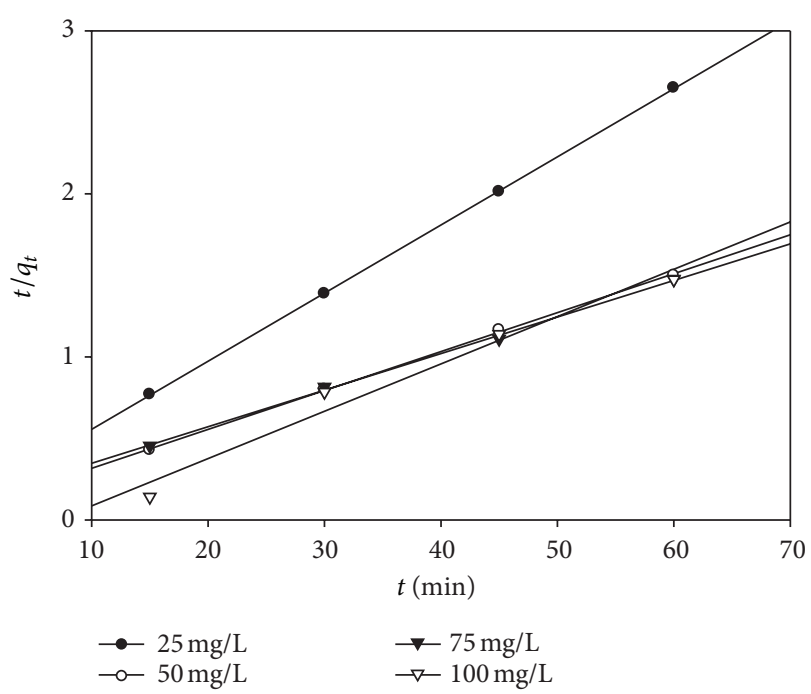

FIgURE 11: The pseudo second-order kinetics for the adsorption of Maxilon Red GRL on sugarcane stalks powder.

$20.96 \mathrm{mg} / \mathrm{g}$ according to Langmuir model. These values obtained from thermodynamic parameters demonstrated that adsorption process is physical in nature and the adsorption process is exothermic and spontaneous. The kinetic evaluation of the adsorption showed that the adsorption is governed by pseudo second-order kinetics.

\section{References}

[1] M. S. Chiou, P. Ho, and H. Y. Li, "Adsorption of anionic dyes in acid solutions using chemically cross-linked chitosan beads," Dyes and Pigments, vol. 60, no. 1, pp. 69-84, 2004.

[2] R. Gong, Y. Ding, M. Li, C. Yang, H. Liu, and Y. Sun, "Utilization of powdered peanut hull as biosorbent for removal of anionic dyes from aqueous solution," Dyes and Pigments, vol. 64, no. 3, pp. 187-192, 2005.

[3] I. A. Şengil and M. Özacar, “The decolorization of C.I. Reactive Black 5 in aqueous solution by electrocoagulation using sacrificial iron electrodes," Journal of Hazardous Materials, vol. 161, no. 2-3, pp. 1369-1376, 2009.

[4] P. S. Kumar, S. Ramalingam, C. Senthamarai, M. Niranjanaa, P. Vijayalakshmi, and S. Sivanesan, "Adsorption of dye from aqueous solution by cashew nut shell: studies on equilibrium isotherm, kinetics and thermodynamics of interactions," Desalination, vol. 261, no. 1-2, pp. 52-60, 2010. 
[5] C. A. Basha, K. V. Selvakumar, H. J. Prabhu, P. Sivashanmugam, and C. W. Lee, "Degradation studies for textile reactive dye by combined electrochemical, microbial and photocatalytic methods," Separation and Purification Technology, vol. 79, no. 3, pp. 303-309, 2011.

[6] M. C. Gutiérrez, M. Pepió, M. Crespi, and N. Mayor, "Control factors in the electrochemical oxidation of reactive dyes," Coloration Technology, vol. 117, no. 6, pp. 356-361, 2001.

[7] M. S. Lucas, A. A. Dias, A. Sampaio, C. Amaral, and J. A. Peres, "Degradation of a textile reactive Azo dye by a combined chemical-biological process: Fenton's reagent-yeast," Water Research, vol. 41, no. 5, pp. 1103-1109, 2007.

[8] I. A. Salem and M. S. El-Maazawi, "Kinetics and mechanism of color removal of methylene blue with hydrogen peroxide catalyzed by some supported alumina surfaces," Chemosphere, vol. 41, no. 8, pp. 1173-1180, 2000.

[9] N. M. Mahmoodi, M. Arami, N. Y. Limaee, and N. S. Tabrizi, "Decolorization and aromatic ring degradation kinetics of direct red 80 by UV oxidation in the presence of hydrogen peroxide utilizing $\mathrm{TiO}_{2}$ as a photocatalyst," Chemical Engineering Journal, vol. 112, no. 1-3, pp. 191-196, 2005.

[10] M. Saquib and M. Muneer, " $\mathrm{TiO}_{2} /$ mediated photocatalytic degradation of a triphenylmethane dye (gentian violet), in aqueous suspensions," Dyes and Pigments, vol. 56, no. 1, pp. 3749, 2003.

[11] N. N. Rao, K. M. Somasekhar, S. N. Kaul, and L. Szpyrkowicz, "Electrochemical oxidation of tannery wastewater," Journal of Chemical Technology and Biotechnology, vol. 76, no. 11, pp. 11241131, 2001.

[12] S. V. Mohan, M. Srimurali, P. Sailaja, and J. Karthikeyan, "A study of acid dye color removal from aqueous solution using adsorption and coagulation," Environmental Engineering Policy, vol. 1, pp. 149-154, 1999.

[13] G. Chen, L. Lei, X. Hu, and P. L. Yue, "Kinetic study into the wet air oxidation of printing and dyeing wastewater," Separation and Purification Technology, vol. 31, no. 1, pp. 71-76, 2003.

[14] J. L. Sotelo, G. Ovejero, J. A. Delgado, and I. Martínez, "Adsorption of lindane from water onto GAC: effect of carbon loading on kinetic behavior," Chemical Engineering Journal, vol. 87, no. 1, pp. 111-120, 2002.

[15] R. Jain and S. Sikarwar, "Adsorptive removal of Erythrosine dye onto activated low cost de-oiled mustard," Journal of Hazardous Materials, vol. 164, no. 2-3, pp. 627-633, 2009.

[16] L. Wang, J. Zhang, R. Zhao, C. Li, Y. Li, and C. Zhang, "Adsorption of basic dyes on activated carbon prepared from Polygonum orientale Linn: equilibrium, kinetic and thermodynamic studies," Desalination, vol. 254, no. 1-3, pp. 68-74, 2010.

[17] L. Abramian and H. El-Rassy, "Adsorption kinetics and thermodynamics of azo-dye Orange II onto highly porous titania aerogel," Chemical Engineering Journal, vol. 150, no. 2-3, pp. 403-410, 2009.

[18] R. A. Shawabkeh and M. F. Tutunji, "Experimental study and modeling of basic dye sorption by diatomaceous clay," Applied Clay Science, vol. 24, no. 1-2, pp. 111-120, 2003.

[19] M. Roulia and A. A. Vassiliadis, "Sorption characterization of a cationic dye retained by clays and perlite," Microporous and Mesoporous Materials, vol. 116, no. 1-3, pp. 732-740, 2008.

[20] A. B. Karim, B. Mounir, M. Hachkar, M. Bakasse, and A. Yaacoubi, "Removal of basic red 46 dye from aqueous solution by adsorption onto Moroccan clay," Journal of Hazardous Materials, vol. 168, no. 1, pp. 304-309, 2009.
[21] H. Chen, J. Zhao, A. Zhong, and Y. Jin, "Removal capacity and adsorption mechanism of heat-treated palygorskite clay for methylene blue," Chemical Engineering Journal, vol. 174, no. 1, pp. 143-150, 2011.

[22] Y. Liu and Y. J. Liu, "Biosorption isotherms, kinetics and thermodynamics," Separation and Purification Technology, vol. 61, no. 3, pp. 229-242, 2008.

[23] A. E. Ofomaja, "Kinetic study and sorption mechanism of methylene blue and methyl violet onto mansonia (Mansonia altissima) wood sawdust," Chemical Engineering Journal, vol. 143, no. 1-3, pp. 85-95, 2008.

[24] A. Witek-Krowiak, R. G. Szafran, and S. Modelski, "Biosorption of heavy metals from aqueous solutions onto peanut shell as a low-cost biosorbent," Desalination, vol. 265, no. 1-3, pp. 126-134, 2011.

[25] M. Koyuncu, "Adsorption properties of basic dyes (Maxilon red GRL and maxilon yellow GRL) onto bentonite," Asian Journal of Chemistry, vol. 21, no. 7, pp. 5458-5464, 2009.

[26] M. Doğan, M. H. Karaoğlu, and M. Alkan, "Adsorption kinetics of maxilon yellow 4GL and maxilon red GRL dyes on kaolinite," Journal of Hazardous Materials, vol. 165, no. 1-3, pp. 1142-1151, 2009.

[27] M. Koyuncu, "Removal of maxilon red GRL from aqueous solutions by adsorption onto silica," Oriental Journal of Chemistry, vol. 25, no. 1, pp. 35-40, 2009.

[28] M. A. Al-Ghouti, M. A. M. Khraisheh, S. J. Allen, and M. N. Ahmad, "The removal of dyes from textile wastewater: a study of the physical characteristics and adsorption mechanisms of diatomaceous earth," Journal of Environmental Management, vol. 69, no. 3, pp. 229-238, 2003.

[29] C. Y. Chen, J. C. Chang, and A. H. Chen, "Competitive biosorption of azo dyes from aqueous solution on the templated crosslinked-chitosan nanoparticles," Journal of Hazardous Materials, vol. 185, no. 1, pp. 430-441, 2011.

[30] D. K. Mahmoud, M. A. M. Salleh, W. A. W. A. Karim, A. Idris, and Z. Z. Abidin, "Batch adsorption of basic dye using acid treated kenaf fibre char: equilibrium, kinetic and thermodynamic studies," Chemical Engineering Journal, vol. 181182, pp. 449-457, 2012.

[31] V. K. Gupta and A. Rastogi, "Biosorption of hexavalent chromium by raw and acid-treated green alga Oedogonium hatei from aqueous solutions," Journal of Hazardous Materials, vol. 163, no. 1, pp. 396-402, 2009.

[32] R. Gong, S. Zhu, D. Zhang, J. Chen, S. Ni, and R. Guan, "Adsorption behavior of cationic dyes on citric acid esterifying wheat straw: kinetic and thermodynamic profile," Desalination, vol. 230, no. 1-3, pp. 220-228, 2008.

[33] O. Hamdaoui, "Batch study of liquid-phase adsorption of methylene blue using cedar sawdust and crushed brick," Journal of Hazardous Materials, vol. 135, no. 1-3, pp. 264-273, 2006.

[34] D. Kavitha and C. Namasivayam, "Experimental and kinetic studies on methylene blue adsorption by coir pith carbon," Bioresource Technology, vol. 98, no. 1, pp. 14-21, 2007.

[35] D. Ghosh and K. G. Bhattacharyya, "Adsorption of methylene blue on kaolinite," Applied Clay Science, vol. 20, no. 6, pp. 295$300,2002$.

[36] G. O. El-Sayed, "Removal of methylene blue and crystal violet from aqueous solutions by palm kernel fiber," Desalination, vol. 272, no. 1-3, pp. 225-232, 2011.

[37] I. Langmuir, "The adsorption of gases on plane surfaces of glass, mica and platinum," The Journal of the American Chemical Society, vol. 40, no. 9, pp. 1361-1403, 1918. 
[38] T. W. Weber and R. K. Chakravorti, "Pore and solid diffusion models for fixed-bed adsorbers," AIChE Journal, vol. 20, no. 2, pp. 228-238, 1974.

[39] H. M. F. Freundlich, "Over the adsorption in solution," Journal of Physical Chemistry, vol. 57, pp. 385-470, 1906.

[40] V. K. Gupta, A. Mittal, L. Krishnan, and V. Gajbe, "Adsorption kinetics and column operations for the removal and recovery of malachite green from wastewater using bottom ash," Separation and Purification Technology, vol. 40, no. 1, pp. 87-96, 2004.

[41] A. K. Jain, V. K. Gupta, A. Bhatnagar, and S. Suhas, "Utilization of industrial waste products as adsorbents for the removal of dyes," Journal of Hazardous Materials, vol. 101, no. 1, pp. 31-42, 2003.

[42] M. Horsfall Jr., A. I. Spiff, and A. A. Abia, "Studies on the influence of mercaptoacetic acid (MAA) modification of cassava (Manihot sculenta Cranz) waste biomass on the adsorption of $\mathrm{Cu}^{2+}$ and $\mathrm{Cd}^{2+}$ from aqueous solution," Bulletin of the Korean Chemical Society, vol. 25, no. 7, pp. 969-976, 2004.

[43] N. T. Abdel-Ghani and G. A. Elchaghaby, "Influence of operating conditions on the removal of $\mathrm{Cu}, \mathrm{Zn}, \mathrm{Cd}$ and $\mathrm{Pb}$ ions from wastewater by adsorption," International Journal of Environmental Science and Technology, vol. 4, no. 4, pp. 451-456, 2007.

[44] S. Lagergren, "About the theory of so-called adsorption of soluble substances," Kungliga Svenska Vetenskapsakademiens Handlingar, vol. 24, no. 4, pp. 1-39, 1898.

[45] Y. S. Ho and G. McKay, "Pseudo-second order model for sorption processes," Process Biochemistry, vol. 34, no. 5, pp. 451465, 1999.

[46] C. Xia, Y. Jing, Y. Jia, D. Yue, J. Ma, and X. Yin, "Adsorption properties of congo red from aqueous solution on modified hectorite: kinetic and thermodynamic studies," Desalination, vol. 265, no. 1-3, pp. 81-87, 2011. 

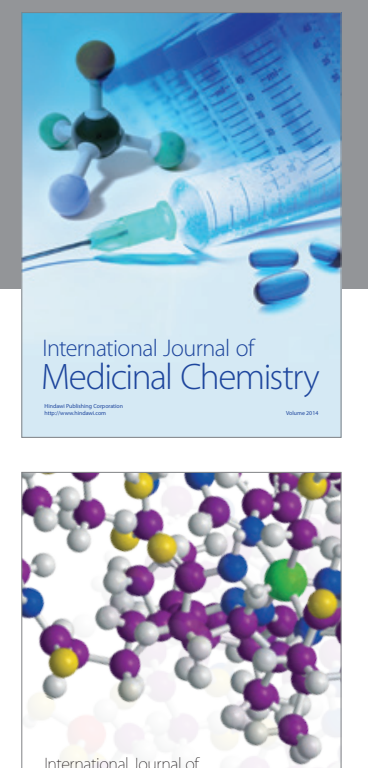

\section{Carbohydrate} Chemistry

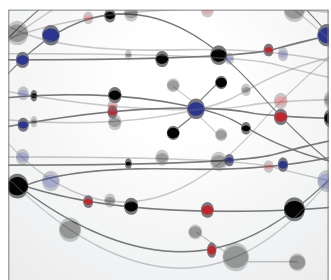

The Scientific World Journal
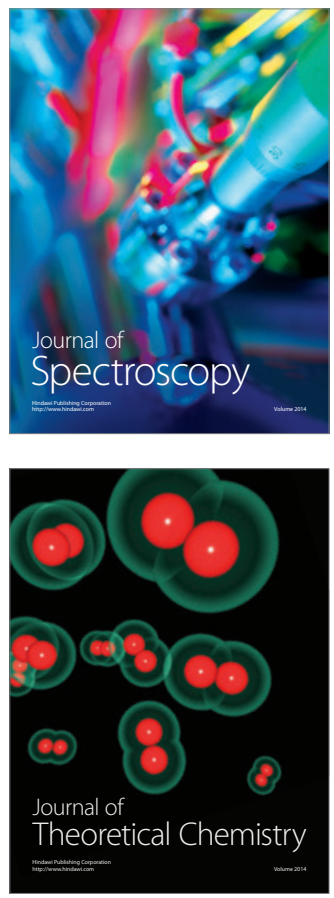
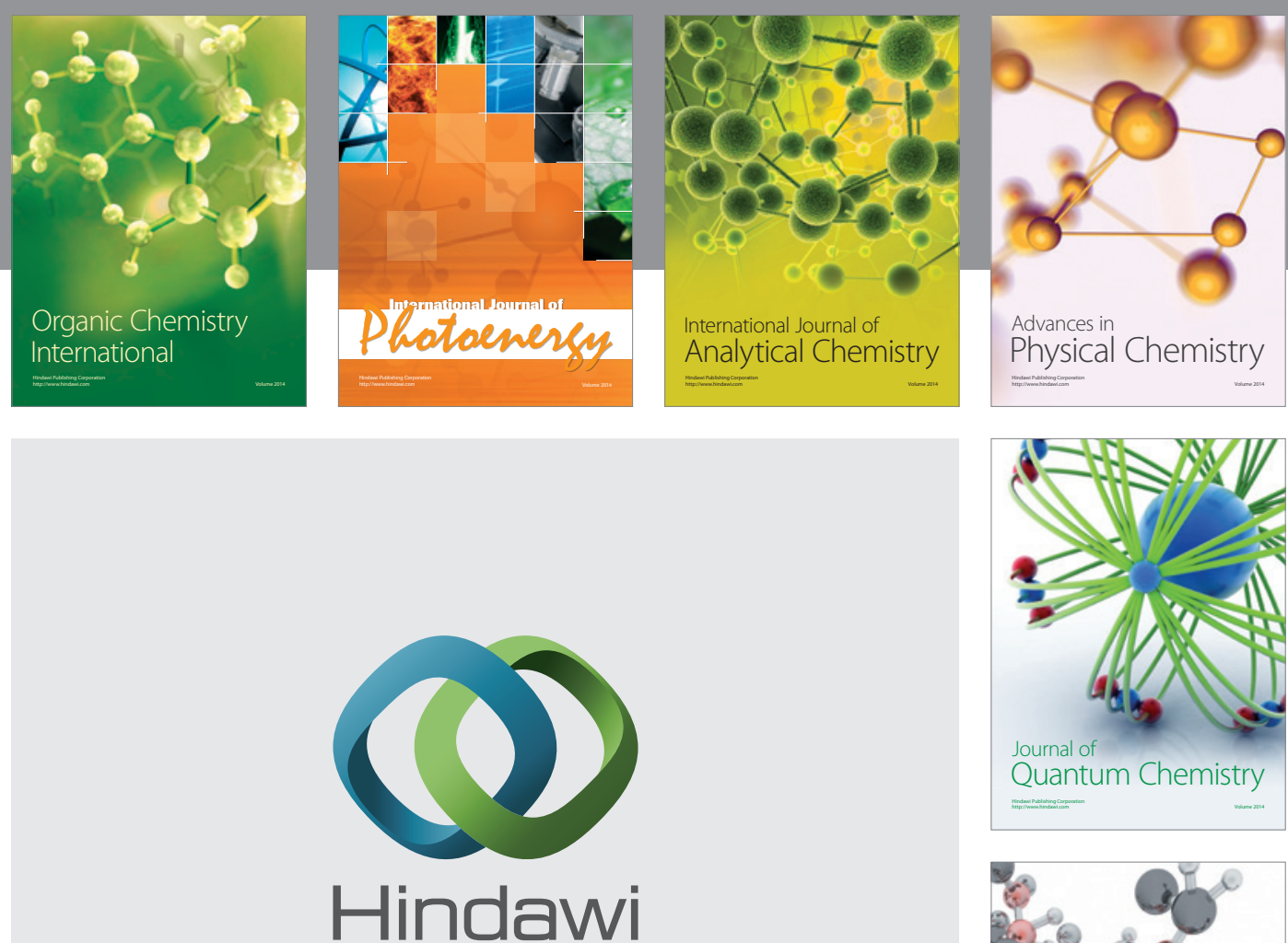

Submit your manuscripts at

http://www.hindawi.com

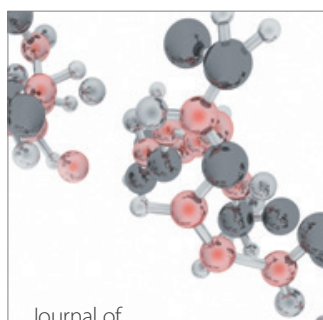

Analytical Methods

in Chemistry

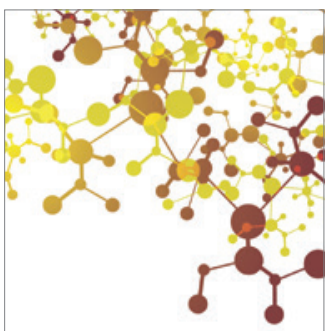

Journal of

Applied Chemistry

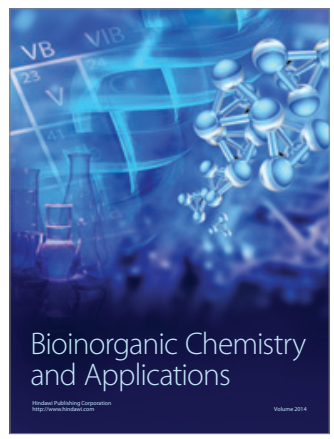

Inorganic Chemistry
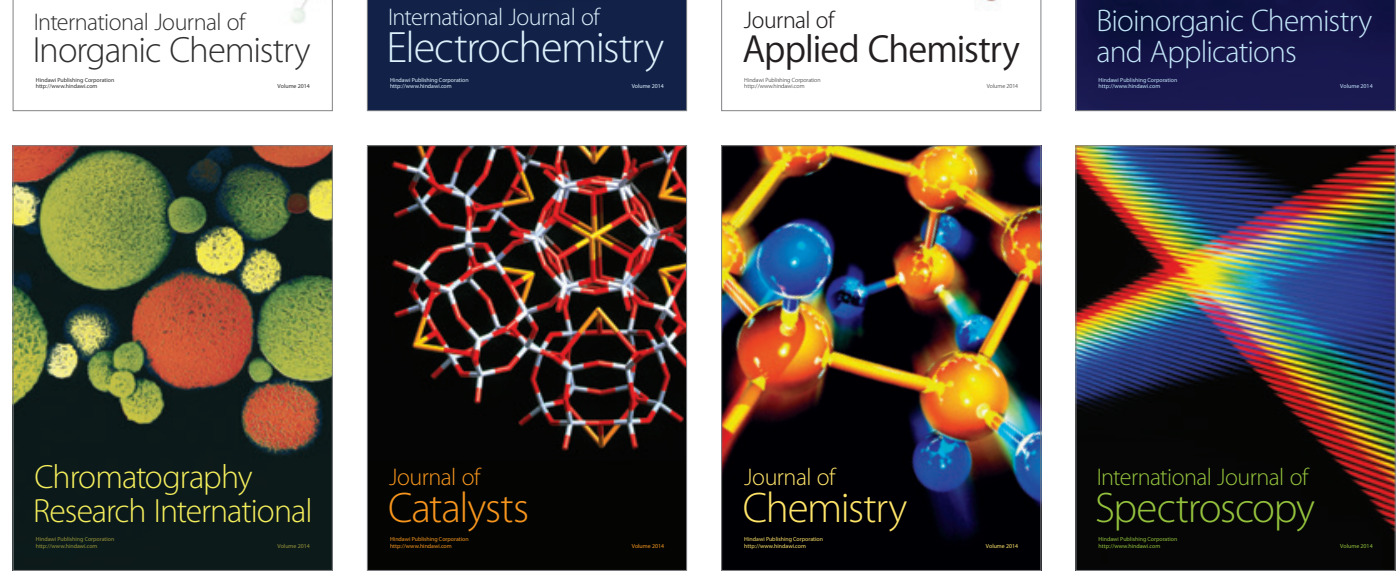